\title{
SURVIVE: let the dead help the living-an autopsy-based cohort study for mapping risk markers of death among those with severe mental illnesses
}

\author{
Jytte Banner ${ }^{1 *}$, Christian Bjerre Høyer ${ }^{2}$, Martin Roest Christensen ${ }^{1}$, Alexandra Gheorghe ${ }^{1}$, Anne Bugge ${ }^{1}$, \\ Gyda Lolk Ottesen', Lene Warner Thorup Boel², Jørgen Lange Thomsen³, Line Kruckow', \\ Christina Jacobsen'
}

\begin{abstract}
'Department of Forensic Medicine, Frederik V's Vej 11, DK-2100 Copenhagen, University of Copenhagen ${ }^{2}$ Department of Forensic Medicine, Palle Juul-Jensens Boulevard 99, DK-8200 Aarhus, University of Aarhus ${ }^{3}$ Department of Forensic Medicine, J. B. Winsløws Vej 17, DK-5000 Odense, University of Southern Denmark *Corresponding Author E-mail: jytte.banner@sund.ku.dk
\end{abstract}

\begin{abstract}
:
Background: Forensic autopsy strategies may improve differential diagnostics both post-mortem and ante-mortem and aid in clinical settings concerning preventive efforts for premature mortality. Excess mortality and reduced life expectancy affect persons with severe mental illnesses (SMI) for multi-faceted reasons that remain controversial. Somatic conditions, medical treatment and lifestyle diseases, which are primarily examined in the living, contribute to premature deaths. The underlying pathophysiological mechanisms are unclear, though, and the benefits of a focused, standardised autopsy remain unproven. We have developed and implemented an optimised molecular-biological autopsy for deceased persons with SMI. Our aim is to map the occurrence of 1) somatic diseases and organ changes; 2 ) metabolic syndrome; 3 ) use and abuse of alcohol, pharmaceuticals and psychoactive substances; 4) pharmacokinetic and pharmacodynamic factors in the metabolism of pharmaceuticals; and 5) genetic variations (acquired and/or congenital) in sudden cardiac death. Additionally, we hope to contribute to diagnostic treatments and preventive measures to benefit those living with SMI. Methods: SURVIVE: let the dead help the living is a prospective, autopsy-based study on 500 deceased persons with SMI subjected to forensic autopsies under the Danish Act on Forensic Inquests and Autopsy. The autopsies followed an extended, standardised autopsy protocol comprised of whole-body computed tomography scanning, magnetic resonance imaging of the heart and brain and an extended forensic autopsy, including a wide panel of analyses (toxicology, microbiology, genetics, histology and biochemical analysis). Additionally, post-mortem data were linked to ante-mortem health data extracted from Danish national health registers.

Discussion: The SURVIVE autopsy procedure, including tissue sampling and bio banking, has been shown to be effective. We expect that the SURVIVE study will provide unique opportunities to unravel the mechanisms and causes of premature death in persons with SMI. We also expect that identifying prognostic biomarkers for comorbidities will contribute to prevention of premature deaths and comorbidities in persons with SMI.
\end{abstract}

Keywords:

Expanded standardised autopsy procedure, molecular autopsy, extended biobanking, premature death markers, severe mental illness

\section{BACKGROUND}

Forensic medical research may play a key note in developing strategies to improve differential diagnostics within the field. These strategies can lead to improved clinical diagnostics and preventive strategies for comorbidities and premature mortality in living patients.

In 2010, the Danish Society of Forensic Medicine and the three Danish sections of forensic pathology, based at the universities of Aarhus, Southern Denmark and Copenhagen reported patterns in the causes of death among deceased individuals with severe mental illnesses (SMI) subjected to forensic autopsies [1]. The report was based on a retrospective study on 516 cases with death certificates indicating diagnoses within sections F20-F29 and F30-39 [2] in the 10th edition of the World Health Organization's International Classification of Diseases (ICD-10). The cause of death in many cases was intoxication, while $10 \%$ died from cardiovascular causes. In $15 \%$ of cases, the cause of death could not be determined after autopsies, a higher rate than in other cases undergoing forensic autopsies in Denmark [1].
Based on this, the project SURVIVE: let the dead help the living-an autopsy-based strategy for mapping risk markers of death among those with severe mental illnesses was launched in May 2013. One aim was to introduce a national, standardised, extended forensic autopsy procedure. The SURVIVE algorithm comprises known risk factors for premature death and comorbidities in persons with SMI, along with anthropometric measures, radiological imaging techniques, biomedical status measures and molecular analysis methods.

The population of people suffering from SMI has higher mortality than the general population [3-6]. Among people suffering from, for example, schizophrenia, mortality is more than double [7], and life expectancy is 25 years lower than in an equivalent group of the general population (standardised mortality rate) [8,9]. Approximately onethirds of deaths among persons with SMI are caused by suicides and accidents, while the remaining two-thirds result from natural causes, with cardiovascular causes accounting for nearly half of these cases [10, 11]. 
However, the underlying reasons for the reduced life expectancy among people with SMI are not sufficiently established. The known risk factors are varied and include cardiovascular diseases (CVD) and lifestyle-related factors, such as diabetes, metabolic syndrome (MetS), obesity, smoking and alcohol and substance use [12-14]. Persons with MetS have increased all-cause mortality and CVD mortality risk [15]. In addition to the risk of intoxication and the detrimental effects of polypharmacy, several antipsychotic and antidepressant pharmaceuticals have been associated with increased risk of sudden cardiac death (SCD) [16-18].

The overall purpose of SURVIVE is to implement an autopsy strategy that can be used to investigate the known risk factors for premature death in a cohort of deceased persons suffering from SMI. These risk factors are lifestyleassociated factors[12], MetS [19], genetic disposition [20], pharmaceuticals [21] and the (ab)use of alcohol and psychoactive substances [22-24]. The aim is to improve differential diagnostics in forensic medicine, clinical diagnostic tools, disease management and treatment in people with SMI within the healthcare sector. No major prospective or systematic autopsy studies have mapped the comorbidities, importance of known risk factors or causes of death in deceased persons with SMI.

\section{RESEARCH QUESTIONS}

The objective of SURVIVE is to develop and employ an optimised, molecularbiological autopsy model for deceased persons with SMI to identify the risk factors and causal pathways for sudden and unexpected death. Four main research questions are proposed:

1) What impacts does CVD have on premature death in the study population? 2) What impacts do adipose tissue changes have on the prevalence and severity of CVD?

3) What impacts do medication and substance use have on premature death?

4) Do genetic and epigenetic mechanisms influence medication- and substance-induced cardiac arrhythmia in the study population?

Areas of interest in SURVIVE include but are not limited to:

- patho-anatomical organ changes

- measurable indicators of MetS

- toxicological analyses

- genetic and epigenetic tests for CVD, mental illnesses and drug metabolism

- development of post-mortem radiological methods with post-mortem computer tomography (PMCT), CT angiography and post-mortem magnetic resonance imaging (PMMRI)

- $\quad$ estimation of the representativeness of the SURVIVE populations for Danish patients with mental illness

\section{METHODS AND DESIGN}

\section{Design}

The SURVIVE study is a national Danish multicentre, prospective, autopsybased cohort study based at the Department of Forensic Medicine, Copenhagen University, conducted in collaboration with the Department of Forensic Medicine, Aarhus University, and the Department of Forensic Medicine, University of Southern Denmark.

\section{Study period}

The study period was 1 May 2013-31 April 2015, and the study sample included 500 deceased individuals (Copenhagen $=313$, Aarhus $=112$, Odense=75).

\section{Study population}

\section{Inclusion criteria}

The project prospectively included all deceased who had known or suspected SMI undergoing forensic autopsy at one of Denmark's three departments of forensic medicine from the $1^{\text {st }}$ of May 2013 and until 500 decedents were included. Upon inclusion of each individual person in the SURVIVE study, the SURVIVE algorithm and workflow were activated. Generally, during the medico-legal inquest, the police decided whether a forensic autopsy should be performed based on the Danish Health Act and the advice of a participating medical health officer or forensic pathologist.

The attending physician determined the presence of SMI or the suspicion of SMI at the time of the medico-legal examination based on information gathered from police reports, next of kin and statements from general practitioners. In some cases, the information was certain and supported a defined diagnosis; in others, it was vague and only indicated suspicion of mental illness. Suspicion included information on treatment with psychotropic pharmaceuticals, defined as prescribed pharmaceuticals with the following codes from The Anatomical Therapeutic Chemical classification system (ATC): N05A, N05B, N06A, N06B and N06C. Decedents receiving N03A pharmaceuticals were included if the indication was due to bipolar or other affective disorders, or the pharmaceutical was N03AE01 (clonazepam). All cases treated with other types of benzodiazepines were included irrespective of the indication. Uncertain information about generic names, tradenames and compounds did not prevent inclusion based on the decision of the attending physician at the department of forensic medicine. The attending physician could at all times confer with a senior physician prior to inclusion or exclusion. Physicians employed by the forensic medical institutes do not have access to the electronic health care files of the health care system and as such, confirmation of a suspicion of SMI was not possible prior to inclusion.

These broad criteria were chosen to avoid missing decedents suffering from an SMI and to include an internal control group of the false positives decedents without SMI that underwent the same specialised autopsy.

\section{Exclusion criteria}

Exclusion criteria were extensive decomposition of the body and if a PMCT scan could not be performed prior to autopsy. Exclusion also happened were the autopsy algorithm would prevent specialised examination required for police investigation (e.g. homicide).Cases in which consent for the SURVIVE project was not given after the autopsy were excluded from further analysis.

\section{Consent}

Under Danish legislation, all research protocols involving biological samples from forensic autopsies require informed consent from the next of kin. A 
detailed plan to contact the next of in was accordingly developed. Written information about the SURVIVE study, including the need for consent and instructions how to contact the research team by email or phone, was mailed by post to the next of kin no less than three months after an autopsy was performed. In the case of no reply, a follow-up phone call was made. All information regarding consent, contact information of next of kin and other comments about the information process was recorded in a separate Microsoft Access $2010^{\text {TM }}$ (Microsoft ${ }^{\oplus}$, Redmond, Washington, USA) database separate from the data registered for the research purposes on each individual case. Cases in which relatives did not give consent were excluded from SURVIVE. Obtaining consent was completed in May 2017, and the consent rate from next of kin was higher than $90 \%$.

\section{Blinding}

All cases were assigned a unique project identification (ID) number (SURVIVEID) upon inclusion in the study. The case ID numbers and the corresponding data were recorded in an Access database. De-anonymisation was done using a separate table linking the project IDs to the social security numbers of the deceased. Police reports, autopsy reports and correspondence concerning individual cases were not recorded in the database. Case-specific results obtained in the SURVIVE project were not available to investigation of individual cases.

\section{SURVIVE protocol}

\section{Post-mortem radiology}

All cases were subjected to whole-body PMCT scanning before autopsy at a department of forensic medicine. Either a Siemens CT scanner Somatom Definition, 64 slice or a Somatom Spirit dual slice was used. Scan protocols adhered to the more recent standards from the Danish Accreditation and Metrology Fund (DANAK) following international standard ISO/IEC 17020:2012. The protocols included both routine scans and scans specifically for individual SURVIVE projects (e.g. cardiac CT, lumbar spine and hips for bone mass density (tables 1-4).

SURVIVE scan protocols for PMCT at the three departments of forensic medicine in Denmark (tables 1-4)

Table 1. CT scan protocol, Department of Forensic Medicine, University of Copenhagen

\begin{tabular}{|c|c|c|c|c|c|}
\hline & Head and neck & Thorax and abdomen & Lower extremities & Cardiac calcium score & Lumbar spine and hips \\
\hline mAs & 260 & 90 & 90 & 157 & 200 \\
\hline $\mathrm{kV}$ & 120 & 120 & 120 & 120 & 120 \\
\hline Slice (mm) & 1.0 & 3.0 & 3.0 & 3.0 & 3.0 \\
\hline Pitch & 0.4 & 0.24 & 0.6 & 0.75 & 0.95 \\
\hline Kernel & $\begin{array}{l}\mathrm{H} 20 \mathrm{~s} \\
\mathrm{H} 60 \mathrm{~s}\end{array}$ & B31f & B31f & B30f & B50f \\
\hline
\end{tabular}

Scanner Siemens Somatom Sensation 4, May-October 2013

Table 2. CT scan protocol, Department of Forensic Medicine, University of Copenhagen

\begin{tabular}{|c|c|c|c|c|c|c|}
\hline & Head and neck & Thorax and abdomen & Lower extremities & Cardiac calcium score & Lumbar spine and hips & Whole body \\
\hline $\mathrm{mAs}$ & 375 & $47 / 40$ & 114 & 147 & 275 & 570 \\
\hline $\mathrm{kV}$ & 140 & 120 & 120 & 120 & 120 & 120 \\
\hline Slice (mm) & 1.0 & $3.0 / 1.0$ & 1.0 & 3 & $3.0 / 1.0$ & 3.0 \\
\hline Pitch & 0.75 & $0.5 / 0.45$ & 0.85 & 0.35 & 0.35 & 1.5 \\
\hline Kernel & $\mathrm{H} 2 \mathrm{Os}$ & B30f/B20f & B20s/B40s & B35f & B2of & B3of \\
\hline
\end{tabular}

Table 3. CT scan protocol, Department of Forensic Medicine, University of Aarhus

\begin{tabular}{|c|c|c|c|c|c|}
\hline & Head and neck & Thorax and abdomen & Lower extremities & Cardiac calcium score & Lumbar spine and hips \\
\hline mAs & 500 & 300 & 200 & 210 & 200 \\
\hline $\mathrm{kV}$ & 140 & 120 & 120 & 120 & 120 \\
\hline Slice $(\mathrm{mm})$ & 1.0 & 1.5 & 1.0 & 3.0 & 3.0 \\
\hline Pitch & 0.75 & 0.5 & 0.85 & 0.5 & 0.95 \\
\hline Kernel & $\begin{array}{c}\mathrm{H} 20 \mathrm{~s} \\
\mathrm{H} 60\end{array}$ & $\begin{array}{l}\text { B2of } \\
\text { B7of }\end{array}$ & $\begin{array}{l}\text { B20s } \\
\text { B40s }\end{array}$ & B35f & B2of \\
\hline
\end{tabular}

Scanner Siemens Somatom Definition, 64 slice, May 2013-May 2015 
Table 4. CT scan protocol, Department of Forensic Medicine, University of Southern Denmark

\begin{tabular}{|c|c|c|c|c|c|c|c|}
\hline & Head & Neck & Thorax & Abdomen & Lower extremities & Cardiac calcium score & Lumbar spine and hips \\
\hline mAs & 110 & 110 & 60 & 80 & 30 & 60 & 30 \\
\hline $\mathrm{kV}$ & 130 & 130 & 130 & 130 & 130 & 130 & 130 \\
\hline Slice (mm) & 3.0 & 3.0 & 5.0 & 5.0 & 5.0 & 3.0 & 3.0 \\
\hline Pitch & 0.95 & 0.95 & 1.8 & 1.8 & 1.0 & 1.0 & 1.0 \\
\hline Kernel & $\begin{array}{l}\text { H31 } \\
\text { H60 }\end{array}$ & B50 & $\begin{array}{l}\text { B31 } \\
\text { B70 }\end{array}$ & B41 & U90 & B31 & U90 \\
\hline
\end{tabular}

Scanner Siemens Somatom Spirit Dual Slice, May 2013-May 2015. Each CT scanner was equipped with a calibration phantom containing different concentrations of hydroxyapatite. The phantoms were supplied by the firm Image Analysis, Inc. Additionally, the CT scanner in Aarhus was equipped with a calibration phantom specifically designed for the measurement of bone mass density by the firm QCT Pro, Mindways Software.

In selected cases, PMCT angiography and PMMRI of the heart and brain were performed.

\section{Extended autopsy algorithm}

The standardised autopsy algorithm followed the most recent accredited standards from DANAK. The SURVIVE algorithm built on it by thoroughly describing the registration of physical parameters and anthropometric measurements and the dissection and sampling of each relevant organ (Table 5), focusing on the dissection and registration of heart parameters (Table 6). Dissection of the heart was performed according to international standards [25].

The material needed for registration, sampling and data collection was supplied in an individually assigned cardboard box with a unique SURVIVEID. The cardboard box was suitable for the autopsy room and provided before the autopsy. Specifically assigned medical personnel performed all registrations before and during each autopsy (see tables 7-8).

\section{Sampling}

The location and sidedness (left or right) of the sample from each organ and tissue were standardised. In addition to the standard autopsy protocol, the samples included peripheral blood and tissue from skeletal muscles, liver, spleen, heart and brain; bone samples from the second lumbar vertebrae and the iliac crest; and hair samples. All tissue and fluid samples were collected in tubes without any additives $(15 \mathrm{~mL}$ and $5 \mathrm{~mL}$, respectively). The relevant samples were stored at $-20^{\circ} \mathrm{C}$ or $-80^{\circ} \mathrm{C}$ until analysis. Tissue for histopathological analyses was fixed in $4 \%$ formalin and then embedded in paraffin. Finally, blood was added to DNA filter paper (FTA ${ }^{\text {TM }}$ Classic Card, Fitzco, Minneapolis, USA) and stored at room temperature for later analyses.

\section{Sample analysis}

Members of the steering group of the SURVIVE-study, who were all certified clinical and forensic pathologists, based histopathological description on a consensus decision. The forensic toxicological analysis after the autopsy was performed at all three forensic chemistry departments following the current DANAK standards under the international standard ISO/IEC 17025:2005. All the toxicological analyses also adhered to an intersectional, approved standard for medication and drug types, analyses matrices and intoxication levels. The analyses comprised screening and quantification of prescribed
Table 5. Registration of physical and organ-specific parameters

\begin{tabular}{cc}
\hline $\begin{array}{c}\text { Registrations of physical para- } \\
\text { meters }\end{array}$ & Organ-specific registrations \\
\hline Height & Brain weight \\
Weight & Thyroid weight \\
Abdominal circumference & Lung weight (left and right) \\
Hip circumference & Omentum weight \\
CRP measurement & Kidney capsule weight \\
Hair length & Spleen weight \\
Hair treatment & Liver weight \\
Hair colour & Liver measurements ( $\mathrm{x} \mid \times \mathrm{d})^{\mathrm{a}}$ \\
& Kidney weight \\
& Kidney measurements $(\mathrm{h} \times \mathrm{x} \times \mathrm{d})^{\mathrm{a}}$ \\
& Heart (see Table 6) \\
\hline
\end{tabular}

a $x \mid x d$ : height $x$ length $x$ depth

pharmaceuticals and illicit psychoactive substances, including active metabolites from several samples (Table 9).

Additional forensic biochemical, microbiological and molecular biology analyses (tables 9 and 10) were performed, including but not limited to post-mortem measurements of blood total cholesterol levels, triglycerides, glycated haemoglobin $(\mathrm{HbA} 1 \mathrm{c})$ and urine-albumin/creatinine ratio.

\section{Other data sources}

The 500 cases were supplemented with register-based data from the Danish national health registers (see Table 11) including, but not limited to: information on dispensed prescription medication, contacts with primary health care providers, admissions to hospitals including emergency wards, ambulatory functions and long term admission, use of involuntary commitment in the psychiatric health care system and registration in substance use treatment facilities,

\section{Study outcomes/SURVIVE-an umbrella for several studies}

SURVIVE has yielded extensive data and bio sampling serving as entry points for sub-projects relevant to premature death and comorbidities in the population with SMI. Furthermore, the SURVIVE study provides opportunities for the development and improvement of autopsy techniques. To answer the central research questions of the SURVIVE study, several PhD students 
Table 6. Registration of cardiac parameters

\begin{tabular}{|c|c|c|c|c|c|}
\hline Heart & $\begin{array}{l}\text { Ventricle measure- } \\
\text { ments }(\mathrm{cm})\end{array}$ & $\begin{array}{c}\text { Ostia } \\
\text { circumference } \\
(\mathrm{cm})\end{array}$ & Coronary artery ostia & $\begin{array}{c}\text { Grade of } \\
\text { coronary artery } \\
\text { disease }\end{array}$ & Morphological change \\
\hline Weight (gram) & $\begin{array}{l}\text { Left ventricle (anterior, } \\
\text { lateral, posterior) }\end{array}$ & Aorta & $\begin{array}{l}\text { Appearance (round, oval } \\
\text { or other) }\end{array}$ & 0 & None \\
\hline \multirow{14}{*}{$\begin{array}{l}\text { Measurements } \\
\mathrm{A} \text { (along the sulcus corona- } \\
\text { rius) } \times \mathrm{B} \text { (perpendicular to } \mathrm{A} \text {, } \\
\text { from the sulcus coronarius } \\
\text { to the apex) } \times C \text { (height of } \\
\text { heart lying on the posterior } \\
\text { side, anterior side facing } \\
\text { upwards) }\end{array}$} & $\begin{array}{l}\text { Right ventricle (anterior, } \\
\text { lateral and posterior) }\end{array}$ & Mitral & $\begin{array}{l}\text { Localisation related to the } \\
\text { commissure (above the } \\
\text { commissure line, in the } \\
\text { commissure line or bene- } \\
\text { ath the commissure line) }\end{array}$ & 1 & Fatty streaks \\
\hline & $\begin{array}{l}\text { Septum (from left to } \\
\text { right ventricle) }\end{array}$ & Tricuspid & $\begin{array}{l}\text { Localisation related to va- } \\
\text { Ive insertion (in insertion, } \\
\text { not in insertion) }\end{array}$ & 2 & Plaque \\
\hline & & Pulmonary & Patency (dia> $2 \mathrm{~mm}$ ) & 3 & Plaque with bleeding \\
\hline & & & & 4 & Arteriosclerosis \\
\hline & & & & $5 \mathrm{~A}$ & $\begin{array}{l}\text { Stenosis } \\
\text { none }\end{array}$ \\
\hline & & & & $5 B$ & Stenosis \\
\hline & & & & & $1 \%-25 \%$ \\
\hline & & & & $5 C$ & Stenosis \\
\hline & & & & & $26 \%-50 \%$ \\
\hline & & & & $5 \mathrm{D}$ & Stenosis \\
\hline & & & & & $51 \%-75 \%$ \\
\hline & & & & $5 \mathrm{E}$ & Stenosis \\
\hline & & & & & $76 \%-99 \%$ \\
\hline & & & & $5 \mathrm{~F}$ & $\begin{array}{c}\text { Occlusion } \\
100 \%\end{array}$ \\
\hline
\end{tabular}

Table 7. Collection of existing demographic, epidemiological and disease-related data connected to project inclusion

\begin{tabular}{cccc}
\hline $\begin{array}{c}\text { General characteri- } \\
\text { stics }\end{array}$ & $\begin{array}{c}\text { Psychiatric } \\
\text { disease }\end{array}$ & $\begin{array}{c}\text { Medication } \\
\text { Lifestyle }\end{array}$ & $\begin{array}{c}\text { Related paraclinical } \\
\text { values (e.g. biochemi- } \\
\text { stry or ECG) }\end{array}$ \\
\hline Date of birth & Schizophrenia & Antipsychotics & Kidneys \\
Date of death & Depression & Antidepressants & Thyroid \\
Gender & Bipolar & Other & Heart \\
Municipality of residence & Other & Cholesterol abuse \\
Next of kin & & CRP \\
Citizenship & & None \\
Ethnicity & & The \\
\hline
\end{tabular}


and postdocs have been enrolled and started 17 subprojects by December 2017 (Table 12).

\section{Statistical considerations}

For each individual subproject, the project team handles the data, supervised by the project manager. Statens Serum Institut, under the Danish Ministry of Health, supports data retrieval and analyses of the national registries. The methods, statistical analysis, programmes and sample size vary among the subprojects. Those involving tissue and fluid analyses use only relevant samples from cases with consent from next of kin, while other subprojects involving only registry- and PMCT/PMMR-scan data have samples from all 500 cases.

\section{Organisation}

The SURVIVE study covers all of Denmark and is embedded in a partnership among the three Danish departments of forensic medicine. Project management is handled by the Department of Forensic Medicine, University of Copenhagen. Several specialised teams have been formed, including data management, pathology, psychiatry, toxicology, genetic, post-mortem radiology, cardiology and registry research groups. See the appendix for the participants and collaborators.

\section{DISCUSSION}

Extended autopsies of persons with SMI may help uncover a range of conditions highly important for the survival of these persons. The project autopsy algorithm enables investigations, sampling and analyses impossible to perform in the living. Not all organ changes can be detected with radiological imaging, biopsies or surgical interventions. Direct observation of organs and subsequent tissue microscopy, forensic toxicological analysis and molecular biological testing may contribute detailed information that substantially supplements the methods applied to examination of the living We expect that by optimising the forensic autopsy of deceased persons with SMI, SURVIVE will increase knowledge of somatic disease, organ change, substance abuse, metabolism of pharmaceuticals and acquired and congenital genetic variations. This knowledge may facilitate the prevention of lower life expectancy and higher mortality among persons with SMI. The symptom complex of lifestyle-related disorders in those with mental illness appears to be an exacerbated version of the general population; therefore, we expect general benefits from the SURVIVE results.

\section{LIMITATIONS AND CONCERNS}

The medicolegal system setting and the Danish Act on Forensic Inquests limit the number of included cases with SMI. The police decide whether further investigations warrant forensic autopsy. Consequently, the SURVIVE study does not include the deaths of persons with SMI the police decide not to refer for forensic autopsies. Deaths not subjected to legal inquest, such as hospital deaths and clinical autopsies performed in hospital settings, are not included. The included cases thus are subject to selection bias. The SURVIVE inclusion criteria are very broad to ensure forming a sufficiently large group of controls that do not fulfil the criteria for a verified diagnosis within the ICD-10 F2 or F3 sections.
Table 8. Tissue samples for histopathology

\begin{tabular}{|c|c|}
\hline Organ & Specific location \\
\hline Omentum & None \\
\hline \multirow[t]{7}{*}{ Brain } & Frontal cortex \\
\hline & Hippocampus \\
\hline & Internal capsule \\
\hline & Pons \\
\hline & Medulla oblongata \\
\hline & Cerebellum \\
\hline & Hypophysis \\
\hline Thyroid gland & Lobe \\
\hline \multirow[t]{2}{*}{ Lung } & Superior lobe \\
\hline & Inferior lobe \\
\hline Lymph node & Bifurcation \\
\hline \multirow[t]{2}{*}{ Aorta } & Sinus part \\
\hline & Abdominal part \\
\hline Spleen & Including capsule \\
\hline Pancreas & Caput \\
\hline \multirow[t]{3}{*}{ Liver } & Anterior \\
\hline & Posterior \\
\hline & Central \\
\hline Kidney & Parenchymatous width \\
\hline \multicolumn{2}{|l|}{ Suprarenal gland } \\
\hline \multirow[t]{2}{*}{ Subcutaneous fat } & Abdomen \\
\hline & Buttock \\
\hline Muscle & M. vastus lateralis \\
\hline Bone marrow & Second lumbar corpora \\
\hline Uterus/prostate & - \\
\hline Ovary/testes & - \\
\hline \multirow[t]{9}{*}{ Heart } & Atrium \\
\hline & Ventricular ejection area \\
\hline & Papillary muscle \\
\hline & Epicardial fat, three areas \\
\hline & Ventricle anterior \\
\hline & Ventricle lateral \\
\hline & Ventricle posterior \\
\hline & Septum anterior \\
\hline & Septum posterior \\
\hline \multirow[t]{4}{*}{ Coronary arteries } & Left coronary artery \\
\hline & Descending branch \\
\hline & Circumflex branch \\
\hline & Right coronary artery \\
\hline
\end{tabular}

SURVIVE is the first Danish forensic research project requiring consent. The setup of the medico-legal system and autopsies required immediate sampling for the study, and it was not possible to ask relatives for informed consent before the autopsies. When contacted several months after the autopsies, many relatives gave consent but also expressed a degree of re-traumatisation by the contact in a situation of grief. Although the final study group of 500 is high by forensic pathology standards, the study group 
Table 9. Aliquot biobank samples and subsequent supplementary analyses

\begin{tabular}{|c|c|c|c|}
\hline Aliquot biobank samples & Toxicology & Microbiology & Clinical biochemistry \\
\hline Blood (peripheral and heart blood) & $\mathrm{x}$ & X (heart blood) & $x$ \\
\hline Spinal fluid & $x$ & $x$ & $x$ \\
\hline Urine & $\mathrm{x}$ & - & $x$ \\
\hline Vitreous humour & $\mathrm{x}$ & - & $\mathrm{x}$ \\
\hline Tonsil tissue & $x$ & $x$ & - \\
\hline Brain tissue & $\mathrm{x}$ & $\mathrm{x}$ & - \\
\hline Heart tissue & $\mathrm{x}$ & $x$ & - \\
\hline Liver tissue & $x$ & $x$ & - \\
\hline Muscular tissue & $\mathrm{x}$ & - & - \\
\hline Lung tissue & - & $\mathrm{x}$ & - \\
\hline Epicardial fat & - & - & - \\
\hline Omentum & - & - & - \\
\hline Abdominal fat & - & - & - \\
\hline Buttocks fat & - & - & - \\
\hline Blood spot/filter paper & - & $x$ & - \\
\hline Hair & $\mathrm{X}$ & - & - \\
\hline Tissue for microscopy (see Table 8) & - & - & - \\
\hline Bone from crista iliaca & - & - & - \\
\hline Lumbar vertebrae corpus & - & - & - \\
\hline
\end{tabular}

is small compared to studies among the living $[6,26,27]$. This poses some constraints for the selection of individual research questions.

\section{ABBREVIATIONS}

AAU-University of Aalborg

AU-University of Aarhus

CT-computed tomography

CVD — cardiovascular disease

DANAK-Danish Accreditation and Metrology Fund

$\mathrm{KU}$-University of Copenhagen

MetS-metabolic syndrome

$\mathrm{MRI}$-magnetic resonance imaging

PMMRI-post-mortem magnetic resonance imaging

PMCT_-post-mortem computed tomography

$\mathrm{RH}$-Rigshospitalet, hospital in Copenhagen

SCD—sudden cardiac death

SDU_University of Southern Denmark

SMI-severe mental illness

SUD_-substance use disorder

\section{DECLARATIONS}

\section{Ethics approval and consent to participate}

The biobank was approved by the Danish Data Protection Agency for Department of Forensic Medicine, University of Southern Denmark (registration number 2013-54-0399), Department of Forensic Medicine, Aarhus University (registration number 2013-54-0400) and Department of Forensic Medicine, University of Copenhagen (registration number 2011-54-
Table 10. Biochemical analyses

\begin{tabular}{ll}
\hline Aliquot biobank sample & Analyses \\
\hline Blood & Triglyceride \\
& Total cholesterol \\
& CRP \\
& HbA1c \\
& Glucose \\
& Creatinine \\
Urine & Albumin \\
\hline
\end{tabular}

1262). Additionally, the project has approval from the National Committee on Health Research Ethics, Denmark (registration number 1305373). Authorisation of data retrieval from several Danish registers was approved by the Danish Data Protection Agency (registration number SUND-2016-06).

Under Danish legislation, all research protocols involving biological samples from forensic autopsies require informed consent from next of kin. Acquisition of consent was completed in May 2017, and the consent rate from next of kin was higher than $90 \%$.

\section{Consent for publication}

Not applicable

\section{Availability of data and material}

The data supporting the study findings are available from the Department of Forensic Medicine, University of Copenhagen. Access to the data is restricted under the license for the current study. The data are not publicly available. 
Table 11. Danish national health register data on psychiatric, physical state and health issues

\begin{tabular}{|c|c|}
\hline Name of national health register & Types of data retrieved for each individual person \\
\hline National Patient Register & $\begin{array}{l}\text { Somatic care: } \\
\text { - Admission and discharge dates } \\
\text { - Reason for admittance } \\
\text { - Diagnoses } \\
\text { - Treatment provided } \\
\text { Psychiatric care: } \\
\text { - Admission and discharge dates } \\
\text { - Reason for admittance } \\
\text { - Self-harm } \\
\text { - Diagnosis } \\
\text { - Treatment provided }\end{array}$ \\
\hline Register of Medicinal Product Statistics & $\begin{array}{l}\text { Medication: } \\
\text { - Prescription } \\
\text { - Dosage } \\
\text { - Date of retrieval of dispensed medication } \\
\text { - Indications for prescription }\end{array}$ \\
\hline National Alcohol Treatment Register & $\begin{array}{l}\text { Alcohol abuse: } \\
\text { - Types of abuse } \\
\text { - Severity } \\
\text { - Substitution medications } \\
\text { - Other types of medication }\end{array}$ \\
\hline Register of Drug Abusers Undergoing Treatment & $\begin{array}{l}\text { Drug abuse: } \\
\text { - Types of abuse } \\
\text { - Drugs in use } \\
\text { - Substitution medications }\end{array}$ \\
\hline Involuntary Commitment Register & $\begin{array}{l}\text { Psychiatric care: } \\
\text { - Start and end date of involuntary commitment } \\
\text { - Type of involuntary commitment used (isolation, electro-shock-therapy, medication, etc) } \\
\text { - Reasons for involuntary commitment }\end{array}$ \\
\hline Danish Psychiatric Central Register & $\begin{array}{l}\text { Psychiatric care: } \\
\text { - Admission and discharge dates } \\
\text { - Reason for admittance } \\
\text { - Self-harm } \\
\text { - Diagnoses } \\
\text { - Treatment provided }\end{array}$ \\
\hline Health Security System & $\begin{array}{l}\text { Primary health care system: } \\
\text { - Contacts } \\
\text { - Type of primary health care practitioner }\end{array}$ \\
\hline
\end{tabular}

Table 13. Subprojects under SURVIVE as of December 2017

\begin{tabular}{|c|c|}
\hline \multicolumn{2}{|c|}{ PhD projects } \\
\hline 1 & Pato-anatomic organ changes: lifestyle or medication \\
\hline 2 & Metabolism and inflammation in fatty tissue \\
\hline 3 & Prognostic markers for cardiovascular disease by calcium score and imaging \\
\hline 4 & Polypharmacy and arrhythmogenic death \\
\hline 5 & Correlation between osteoporosis and treatment with antipsychotic medications \\
\hline 6 & Identifying the mechanisms underlying premature death in persons suffering from \\
\hline & schizophrenia or severe depression, a registry-based study \\
\hline 7 & Hair analysis for medications, illicit substances and the stress cursor cortisol \\
\hline 8 & Analysis of medication and illicit substances in tissues and biological fluids to understand the unexpected deaths of mentally ill individuals \\
\hline 9 & Stress-related morphological changes \\
\hline \multicolumn{2}{|c|}{ Postdoc projects } \\
\hline 10 & Genetic-associated arrhythmias vs sudden cardiac death \\
\hline 11 & Heart morphology and MRI, T2 quantification \\
\hline 12 & Epigenetics: drug-induced sudden cardiac death among individuals with schizophrenia \\
\hline \multicolumn{2}{|c|}{ Scholarships } \\
\hline 13 & Kidney damage: pharmacologically induced kidney injury in individuals with schizophrenia \\
\hline 14 & Virtual organ measurement (CT \& MRI): method development \\
\hline 15 & Obesity and fatty hearts \\
\hline 16 & CT-based volumetric study of hippocampus \\
\hline 17 & Steatosis myocardii, fatty infiltration in the myocytes \\
\hline
\end{tabular}


However, data can be made available from the authors upon reasonable requests and with permission from the Danish Data Protection Agency.

\section{Competing interests}

The authors declare that they have no conflicts of interest.

\section{Funding}

The SURVIVE project received funding of approximately 20 million DKK from the University of Copenhagen, Aarhus University, University of Southern Denmark, Region of Southern Denmark, Governmental by SATS-puljen, Lundbeck Foundation, Novo Nordisk Foundation, Augustinus Foundation, Oda og Hans Svenningsens Foundation, Aase og Ejnar Danielsens Foundation, Jens Anker Andersens Foundation, Danish Heart Association, Danish Research Council and Medical Society of Copenhagen.

\section{Authors' contributions}

JBAN and CBH designed the study and obtained funding. JLT, GLO and LWB contributed to the study implementation. $C B H, M R C, A G G, A B$ and $C J$ contributed to designing and arranging the logistics and implementing the algorithm. CJ, PL and LWB designed the PMCT scan protocols. LKR collected the registry data and drafted the second version of the manuscript. MRC, AGG and $\mathrm{CJ}$ obtained consent from the next of kin. AGG analysed all the PMCT scans for calcium scores. CJ and JBAN wrote the first draft of the manuscript. The other authors critically reviewed the manuscript for intellectual content. All the authors read and approved the final manuscript.

\section{ACKNOWLEDGEMENTS}

We thank the staff, doctors, secretaries and forensic and laboratory technicians at the three forensic medicine departments, without whose engagement and participation this study would not have succeeded.

\section{REFERENCES}

[1] Thomsen JL, Banner J: Der dør for mange psykiatriske patienter: Sundhedsstyrelsen bør se nærmere på registreringen af dødsårsager. Ugeskrift for læger 2010, 172(33):2256-2257.

[2] Organization WH: The ICD-10 classification of mental and behavioural disorders: clinical descriptions and diagnostic guidelines, vol. 1: World Health Organization; 1992.

[3] Whiteford HA, Degenhardt L, Rehm J, Baxter AJ, Ferrari AJ, Erskine HE, Charlson FJ, Norman RE, Flaxman AD, Johns $\mathrm{N}$ et al: Global burden of disease attributable to mental and substance use disorders: findings from the Global Burden of Disease Study 2010. Lancet 2013, 382(9904):1575-1586.

[4] Wahlbeck K, Westman J, Nordentoft M, Gissler M, Laursen TM: Outcomes of Nordic mental health systems: life expectancy of patients with mental disorders. The British Journal of Psychiatry 2011, 199(6):453-458.

[5] Laursen TM, Musliner KL, Benros ME, Vestergaard M, Munk-Olsen T: Mortality and life expectancy in persons with severe unipolar depression. Journal of Affective Disorders, 193:203-207.

[6] Nordentoft M, Wahlbeck K, Hällgren J, Westman J, Ösby U, Alinaghizadeh H, Gissler M, Laursen TM: Excess Mortality, Causes of Death and Life Expectancy in 270,770 Patients with Recent Onset of Mental Disorders in Denmark, Finland and Sweden. PLOS ONE 2013, 8(1):e55176.

[7] Chang CK, Hayes RD, Broadbent M, Fernandes AC, Lee W, Hotopf M, Stewart R: All-cause mortality among people with serious mental illness (SMI), substance use disorders, and depressive disorders in southeast London: a cohort study. BMC Psychiatry 2010, 10:77.

[8] Tiihonen J, Lonnqvist J, Wahlbeck K, Klaukka T, Niskanen L, Tanskanen A, Haukka J: 11-year follow-up of mortality in patients with schizophrenia: a populationbased cohort study (FIN11 study). Lancet 2009, 374(9690):620-627.

[9] Leucht S, Burkard T, Henderson J, Maj M, Sartorius N: Physical illness and schizophrenia: a review of the literature. Acta Psychiatr Scand 2007, 116(5):317333.

[10] Brown S, Inskip H, Barraclough B: Causes of the excess mortality of schizophrenia. BrJ Psychiatry 2000, 177:212-217.
[11] De Hert M, Detraux J, van Winkel R, Yu W, Correll CU: Metabolic and cardiovascular adverse effects associated with antipsychotic drugs. Nat Rev Endocrinol 2011, 8(2):114-126.

[12] Oud MJ, Meyboom-de Jong B: Somatic diseases in patients with schizophrenia in general practice: their prevalence and health care. BMC Fam Pract 2009, 10:32.

[13] Megna JL, Schwartz TL, Siddiqui UA, Herrera Rojas M: Obesity in adults with serious and persistent mental illness: a review of postulated mechanisms and current interventions. Ann Clin Psychiatry 2011, 23(2):131-140.

[14] Vancampfort D, Stubbs B, Mitchell AJ, De Hert M, Wampers M, Ward PB, Rosenbaum S, Correll CU: Risk of metabolic syndrome and its components in people with schizophrenia and related psychotic disorders, bipolar disorder and major depressive disorder: a systematic review and meta-analysis. World Psychiatry 2015, 14(3):339-347.

[15] Mottillo S, Filion KB, Genest J, Joseph L, Pilote L, Poirier P, Rinfret S, Schiffrin EL, Eisenberg MJ: The Metabolic Syndrome and Cardiovascular Risk: A Systematic Review and Meta-Analysis. Journal of the American College of Cardiology 2010, 56(14):1113-1132.

[16] Weeke P, Jensen A, Folke F, Gislason GH, Olesen JB, Andersson C, Fosbol EL, Larsen JK, Lippert FK, Nielsen SL et al: Antidepressant use and risk of out-of-hospital cardiac arrest: a nationwide case-time-control study. Clin Pharmacol Ther 2012, 92(1):72-79.

[17] Ray WA, Chung CP, Murray KT, Hall K, Stein CM: Atypical Antipsychotic Drugs and the Risk of Sudden Cardiac Death. The New England journal of medicine 2009, 360(3):225-235.

[18] Wu CS, Tsai YT, Tsai HJ: Antipsychotic Drugs and the Risk of Ventricular Arrhythmia and/or Sudden Cardiac Death: A Nation-wide Case-Crossover Study. Journal of the American Heart Association: Cardiovascular and Cerebrovascular Disease 2015 4(2):e001568.

[19] Alberti KG, Eckel RH, Grundy SM, Zimmet PZ, Cleeman Jl, Donato KA, Fruchart JC, James WP, Loria CM, Smith SC, Jr. et al: Harmonizing the metabolic syndrome: a joint interim statement of the International Diabetes Federation Task Force on Epidemiology and Prevention; National Heart, Lung, and Blood 
Institute; American Heart Association; World Heart Federation; International Atherosclerosis Society; and International Association for the Study of Obesity. Circulation 2009, 120(16):1640-1645.

[20] Identification of risk loci with shared effects on five major psychiatric disorders: a genome-wide analysis. The Lancet 2013, 381(9875):1371-1379.

[21] Newcomer JW: Second-generation (atypical) antipsychotics and metabolic effects: a comprehensive literature review. CNS Drugs 2005, 19 Suppl 1:1-93.

[22] Beijer U, Andreasson A, Agren G, Fugelstad A: Mortality, mental disorders and addiction: a 5-year follow-up of 82 homeless men in Stockholm. Nord J Psychiatry 2007, 61(5):363-368.

[23] Nyhlén A, Fridell $M$, Bäckström $M$, Hesse $M$, Krantz P: Substance abuse and psychiatric co-morbidity as predictors of premature mortality in Swedish drug abusers a prospective longitudinal study 1970 - 2006. BMC psychiatry 2011, 11(1):122.

[24] Hjorthøj C, Østergaard MLD, Benros ME, Toftdahl NG, Erlangsen A, Andersen JT, Nordentoft M: Association between alcohol and substance use disorders and all-cause and cause-specific mortality in schizophrenia, bipolar disorder, and unipolar depression: a nationwide, prospective, register-based study. The Lancet Psychiatry 2015, 2(9):801-808.

[25] Basso C, Burke M, Fornes P, Gallagher PJ, de Gouveia RH, Sheppard M, Thiene $G$, van der Wal A: Guidelines for autopsy investigation of sudden cardiac death. Virchows Archiv 2008, 452(1):11-18.

[26] Tidemalm D, Waern M, Stefansson C-G, Elofsson S, Runeson B: Excess mortality in persons with severe mental disorder in Sweden: a cohort study of 12103 individuals with and without contact with psychiatric services. Clinical Practice and Epidemiology in Mental Health: CP \& EMH 2008, 4:23-23.

[27] Jones ME, Campbell G, Patel D, Brunner E, Shatapathy CC, Murray-Thomas T, van Staa TP, Motsko S: Risk of Mortality (including Sudden Cardiac Death) and Major Cardiovascular Events in Users of Olanzapine and Other Antipsychotics: A Study with the General Practice Research Database. Cardiovasc Psychiatry Neurol 2013, 2013:647476. 


\section{APPENDIX}

\section{Participants}

Forensic pathology: Professor Jytte Banner, KU; Deputy Chief Forensic Pathologist Christina Jacobsen, KU; Professor Lene Warner Thorup Boel, AU; former Deputy Chief Forensic Pathologist Gyda Lolk Ottesen, KU; Professor Emeritus Jørgen Lange Thomsen, SDU; Deputy Chief Forensic Pathologist Peter Thiis Knudsen, SDU;

Clinical pathology: Professor Ulrik Baandrup, AAU; Professor Niels Marcussen, SDU;

Clinical associate professor Sönke Detlefsen, SDU;

Psychiatry: Professor Merete Nordentoft, KU; Professor Martin Balslev, KU; Clinical associate professor John Teilmann Larsen, SDU;

Cardiology: Clinical associate professor Klaus Fuglsang Kofoed, RH; Dr. Niels Vejlstrup, $\mathrm{RH}_{\text {; }}$

Toxicology: Professor Kristian Linnet, KU; Associate professor Sys Stybe Johansen, KU; Senior researcher Jørgen Hasselstrøm, AU; forensic chemist Jakob Jornil, AU;

Radiology: Professor Carsten Thomsen, RH; Dr. Karl Erik Jensen, $\mathrm{RH}$;

Osteology: Professor Ellen Magrethe Hauge, AU; Associate Professor Michel Dalstra, $\mathrm{AU}$;

Genetics: Professor Niels Morling, KU; Senior consultant Claus Børsting, KU;

Statistics: Professor Claus Ekstrøm, KU; Senior researcher Heather Boyd, SSI, KU; Professor Niels Lynnerup, KU;

Pharmacology: Professor Jørgen Rungby, AU, KU;

Anthropology: Professor Niels Lynnerup, KU;

Neuroanatomy: Professor Emeritus Morten Møller, KU; 